OPEN ACCESS

Edited by:

Liang Wu,

Chongqing University, China

Reviewed by:

Yaming Wang,

Harbin Institute of Technology, China

Zhihui Xie,

China West Normal University, China

*Correspondence:

You Zhang

youzhang@bipt.edu.cn

Xuelong HaO

x/haogrinm@126.com

Specialty section: This article was submitted to

Structural Materials,

a section of the journal

Frontiers in Materials

Received: 07 July 2021 Accepted: 13 August 2021 Published: 23 September 2021

Citation:

Zhang Y, Wang J, Zhang Z, Wei K, Zhang Z, Hao $X$ and Chen $F$ (2021)

Silane-Modified Graphene Oxide Composite as a Promising Corrosion-

Inhibiting Film for Magnesium

Alloy AZ31.

Front. Mater. 8:737792.

doi: $10.3389 /$ fmats.2021.737792

\section{Silane-Modified Graphene Oxide Composite as a Promising Corrosion-Inhibiting Film for Magnesium Alloy AZ31}

\author{
You Zhang ${ }^{1 *}$, Juping Wang ${ }^{1}$, Zheng Zhang ${ }^{1}$, Kai Wei ${ }^{1}$, Zhe Zhang ${ }^{1}$, Xuelong Hao ${ }^{2,3 *}$ and \\ Fei Chen ${ }^{1}$
}

${ }^{1}$ College of New Materials and Chemical Engineering, Beijing Institute of Petrochemical Technology, Beijing, China, ${ }^{2}$ General Research Institute for Nonferrous Metals, Beijing, China, ${ }^{3}$ China United Testing and Certification Co., Ltd., Beijing, China

In this study, (3-aminopropyl)-triethoxysilane-modified graphene oxide (GO) composite thin films were synthesized on magnesium alloy AZ31 substrate. The structure, composition, and morphology of silane-GO films were analyzed. Electrochemical measurements and immersion tests showed that silane-GO coatings provide effective protection for magnesium alloy substrates, owing to the good barrier property of the layered GO, and decrease the defects on the GO film surface due to the silane modification. In addition, the corrosion product between the outer silane-GO film and Mg alloy substrate also improved the corrosion resistance of the Mg alloy. Thus, silane-GO composite thin films provide an effective approach for protecting the lightweight metal substrate.

Keywords: graphene oxide, silane, film, corrosion resistance, Mg alloy

\section{INTRODUCTION}

In recent years, magnesium alloys have gained considerable attention due to their remarkable mechanical and biodegradable properties (Wu et al., 2013; Zainal Abidin et al., 2013; HernándezBarrios et al., 2020; Daavari et al., 2021). With numerous magnesium alloy applications, the problem of corrosion resistance has been obstructing their further use in many specific situations (Gnedenkov et al., 2016; Pan et al., 2016; Zhou et al., 2020). Therefore, some experiments have been carried out to improve the corrosion resistance of magnesium alloys.

Graphene, as a 2D layer of sp2-hybridized carbon atoms, has gained significant attention for metal protection (Prasai et al., 2012; Hsieh et al., 2014; Kyhl et al., 2015) due to its unique properties, such as excellent mechanical property, thermal and chemical stability, gas impermeability, higher aspect ratio, lower density, and good barrier property (Aneja et al., 2017; Jo et al., 2017). However, owing to the high electrical conductivity of graphene, the galvanic corrosion of the metal can be greatly promoted when corrosion occurs in the defects (such as cracks or wrinkles) of graphene layers, severely bring down the corrosion resistance in the long term (Lei et al., 2017; Sanjid et al., 2019).

Graphene oxide (GO), possessing plenty of oxygen functional groups on its basal planes and edges, has gathered equal attention because of its useful metal protection properties. Generally, GO and modified GO sheets can be used as nano-additives to enhance the anticorrosive properties of organic coatings. Some researchers (Chang et al., 2012; Yu et al., 2014) prepared GO-reinforced composite coatings, which exhibited strong resistance to oxidation and corrosion, using the chemical modification method. However, many researchers have found that simple doping of GO 
cannot decrease their surface energy, which is the reason they tend to agglomerate. Several recent studies (Wan et al., 2014; Sun et al., 2015; Ma et al., 2016; Ramezanzadeh et al., 2016) have shown that GO can be covalently functionalized with silane and then embedded into an organic coating to improve the barrier property of the coating by suppressing the penetration of an aggressive medium. Meanwhile, the covalent bond ( $\mathrm{Si}-\mathrm{O}-\mathrm{Me}$ ) can be formed by the reaction of silane with the hydroxyl groups on the metal surface (Me-OH) (Liu et al., 2015a; Yu et al., 2015; Matinlinna et al., 2018; Fernández-Hernán et al., 2021).

Therefore, in order to inhibit the agglomeration of GO in coatings, the GO can be modified using silane coupling agents to reduce their surface energy. In addition, the silane can be linked with a metal substrate with covalent bonding, ensuring a high adhesion strength between the coating and the substrate.

In this study, a (3-aminopropyl)-triethoxysilane (APS)-modified GO film was prepared on the surface of magnesium alloy to investigate the effect of silane-grafted GO on corrosion resistance of the as-obtained coating. It is expected that by applying the APS agent as a "bridge" to covalently link GO to the magnesium alloy substrate, the silane-GO film with good adhesion strength and corrosion resistance property would be realized.

\section{EXPERIMENTAL SECTION}

\section{Materials}

Magnesium alloy AZ31 sheets of size $30 \mathrm{~mm} \times 30 \mathrm{~mm} \times 5 \mathrm{~mm}$ (approximate minority components, wt.\%: $\mathrm{Al} 3.19, \mathrm{Zn} 0.81, \mathrm{Mn}$ 0.33 , and balance $\mathrm{Mg}$ ) were used as substrate materials in this study. Before coating, the samples were ground with $\mathrm{SiC}$ paper to 2000 grit. All specimens were rinsed in distilled water, then cleaned ultrasonically in alcohol for $10 \mathrm{~min}$, and eventually dried in warm air. Graphene oxide $(10 \mathrm{ml} / \mathrm{L}, 5 \mathrm{wt} . \%$, with few layers) was purchased from Beijing Carbon Century Technology Co., Ltd., China. 3-Aminopropyl-triethoxysilane (analytical grade) was purchased from Beijing J\&K, China. Alcohol and glacial acetic acid (analytical grade) were purchased from Beijing Chemical Works, China.

\section{Silanization of GO and Preparation of Silane-GO Film on Magnesium Alloy}

$0.1 \mathrm{~g}$ GO powders were ultrasonically dispersed into $50 \mathrm{ml}$ deionized water for $8 \mathrm{~h}$. Then, $150 \mathrm{ml}$ of alcohol was added to the mixture under vigorous stirring to obtain a GO suspension $(\sim 0.5 \mathrm{mg} / \mathrm{ml})$. After that, $2 \mathrm{ml}$ APS was added into the suspension gradually. Such low APS concentration was used to obtain a graphene-based film rather than a silane-based film. Then, the $\mathrm{pH}$ of the suspension was adjusted to 5 using glacial acetic acid. In this way, the hydrolysis reaction of APS was promoted, and the condensation reaction was restrained. The mixture was sealed and continuously stirred for $12 \mathrm{~h}$ at $50{ }^{\circ} \mathrm{C}$, forming a silane-GO suspension. In addition, APS solution with 1 vol. \% was prepared by combining APS, glacial acetic acid, deionized water, and alcohol, and then stirred for $12 \mathrm{~h}$ at $50{ }^{\circ} \mathrm{C}$ as a comparison.

The preparation of films was carried out using a dip coater (PTLMM01, China) at room temperature. The pretreated Mg alloy samples were immersed into the silane-GO suspension for $5 \mathrm{~min}$, then taken out at the speed of $200 \mathrm{~mm} / \mathrm{min}$, and subsequently cured at room temperature for $15 \mathrm{~min}$. The above process was performed twice. Finally, the samples were cured at $60^{\circ} \mathrm{C}$ for $60 \mathrm{~min}$. All samples were kept in a drying chamber for more than $24 \mathrm{~h}$ before use. The synthesis and silanization of GO and the preparation of silane-GO (GOAPS) films on $\mathrm{Mg}$ alloy are depicted schematically in Figure $\mathbf{1 .}$

\section{Characterization}

The zeta potentials of GO, APS, and GO-APS in suspension were measured using a nanoparticle analyzer (Malvern Zetasizer Nano, UK) to evaluate the stability of the solution. The electrical conductivity of GO and GO-APS powder was measured using a resistivity tester (SZT-D, China) to evaluate the effect of GO and GO-APS on the corrosion process. Atomic force microscopy (AFM; SPM9500-J3) of GO and GO-APS sheets was carried out through drop-casting deposition on a silicon wafer. The surface morphology of films was examined using a field-emission scanning electron microscope (SEM; JEOL JSM-7800) at the voltage of $20 \mathrm{kV}$. The structure of films was characterized by Raman spectra (Model Laboratory RAM HR800, HORIBA Jobin Yvon) through a $50 \times$ objective $(\mathrm{NA}=0.5)$ with a $514.5-\mathrm{nm} \mathrm{Ar}-\mathrm{Kr}$ laser. To avoid laser-induced thermal damage, the power of the laser was kept at $0.4 \mathrm{~mW}$ on the sample. Adhesion testing was carried out by the pull-off test as per the EN-ISO 4624 standard by using a CMT5504 machine at a crosshead speed of $2 \mathrm{~mm} / \mathrm{min}$. Glow discharge optical emission spectroscopy (GDOES; HORIBA GD-Profiler 2) depth profile analysis of the coated samples was measured at a pressure of $650 \mathrm{~Pa}$ and power of $30 \mathrm{~W}$ with an anode $4 \mathrm{~mm}$ in diameter.

\section{Electrochemical Measurements}

Electrochemical impedance spectra (EIS) measurements were carried out on an electrochemical workstation (CS360) by using a three-electrode system in $0.05 \mathrm{M} \mathrm{NaCl}$ aqueous solution. A low concentration of the $\mathrm{NaCl}$ solution was used to decrease the rate of the corrosion processes and allow a more correct estimation of the processes at the early stages ( $\mathrm{Yu}$ et al., 2015). A saturated calomel electrode (SCE) was used as the reference electrode, a platinum plate as the counter electrode, and film-coated samples as the working electrode. After immersion in $0.05 \mathrm{M} \mathrm{NaCl}$ aqueous solution for $1 \mathrm{~h}$, the open-circuit potential (OCP) of the films was monitored continuously. The frequency range of EIS measurements was from $100 \mathrm{kHz}$ to $10 \mathrm{mHz}$ with an $\mathrm{AC}$ excitation amplitude of $10 \mathrm{mV}$.

\section{RESULTS AND DISCUSSION}

Figure 2 shows the Zeta potential of APS, GO, and GO-APS stable and homogeneous sols. The Zeta potential of the GO 


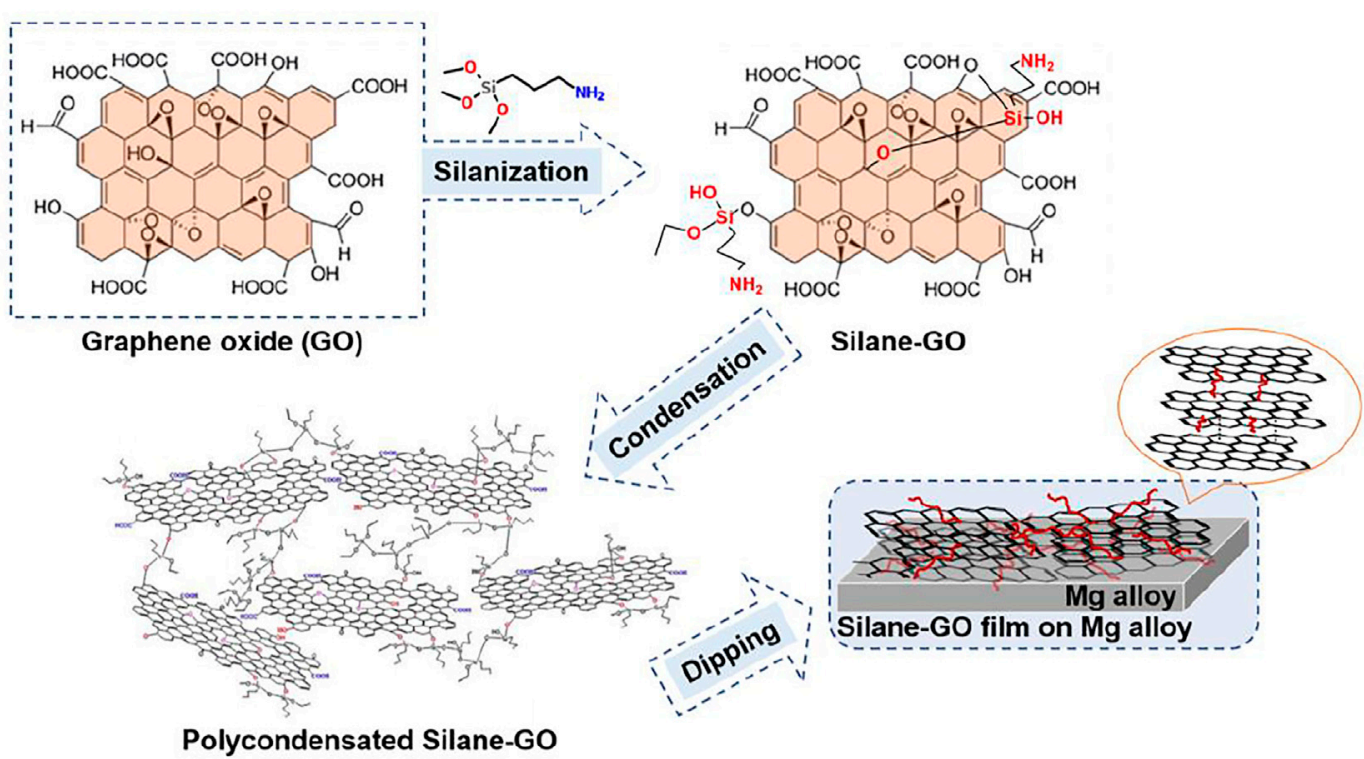

FIGURE 1 | Schematic representation of the synthesis and silanization of GO and the preparation of silane-GO films on the Mg alloy.

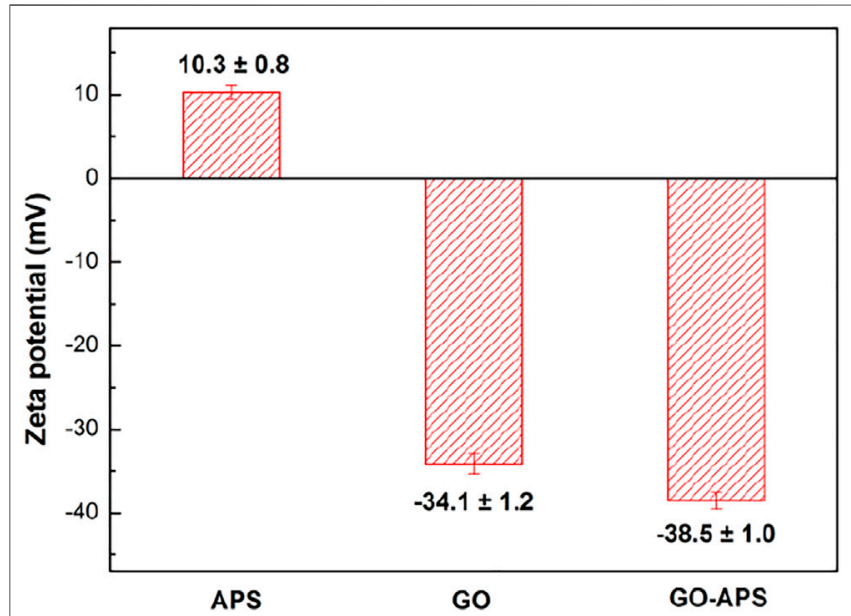

FIGURE 2 |Zeta potential of stable and homogeneous sols: (A) APS; (B) GO; (C) GO-APS.

suspension after silane modification is close to that of the GO suspension, which is more negative than that of APS sol, indicating that the main component of the GO suspension after silane modification is GO instead of cross-linked APS sol particles. Comparing the conductivity of the GO with silanemodified GO effect on the corrosion process with the GO with the APS-modified GO powder using the conductivity test, the results showed that the conductivity of the silane-modified GO becomes lower, mainly because of a nonconductive organic silane group grafted to the surface of the GO (Yu et al., 2015).

AFM observation of GO and GO-APS deposited on a silicon wafer through drop-casting was carried out. Representative AFM images of GO and GO-APS are shown in Figure 3. There is no apparent decrease in thickness of GO-APS by the presence of silane chains grafted on the GO surface, but with the GO layers of local fragmentation.

The FE-SEM images of GO, APS, and GO-APS film-coated $\mathrm{Mg}$ alloy samples are displayed in Figure 4. Under the action of the film-forming liquid, a layer of sheet structure vertical to the surface of the substrate was formed between the film and the substrate due to the rapid dissolution of the magnesium surface. On the surface of the GO film sample, the sheet GO coating on the surface is not continuously dense. The defects can be significantly seen from the partial enlargement of Figure $\mathbf{4} \mathbf{A}_{2}$. The APS film surface has a magnesium alloy corrosion product layer, while no corrosion products of the magnesium alloy surface layer were found on the silane-modified GO layer. The surface layer has continuous density, and the GO of the lamella is evenly distributed in the layer, showing that APS plays an important role in improving the uniformity of the GO film. Moreover, the GO film is partially accumulated after modification by APS as shown in Figure $\mathbf{4} \mathbf{C}_{2}$.

Figure 5 presents the Raman spectra of GO, APS, and GOAPS films deposited on Mg alloys. The APS-silane film shows almost no obvious peak near $1,500 \mathrm{~cm}^{-1}$. Two obvious peaks are detected in GO and GO-APS films, which are ascribed to the structural defects of the GO membrane of carbon (Ferrari et al., 2006; Ma et al., 2019). The spectrum of the GO film displays the $G$ peak and the D peak at $1,352 \mathrm{~cm}^{-1}$ and $1,589 \mathrm{~cm}^{-1}$, respectively, which are consistent with the results of other researchers ( $\mathrm{Yu}$ et al., 2015; Zhang et al., 2018). The D peak is caused by the disorder of C-C key vibration, characterization of the $\mathrm{sp}^{3}$ hybridization structure of carbon atoms; the $\mathrm{G}$ peak is caused by the stretching vibration of $\mathrm{C}-\mathrm{C}$ bonds and represents the carbon atoms of the $\mathrm{sp}^{2}$ hybridized structure (Stankovich et al., 2007). After the modification of APS, the positions of D peak and 

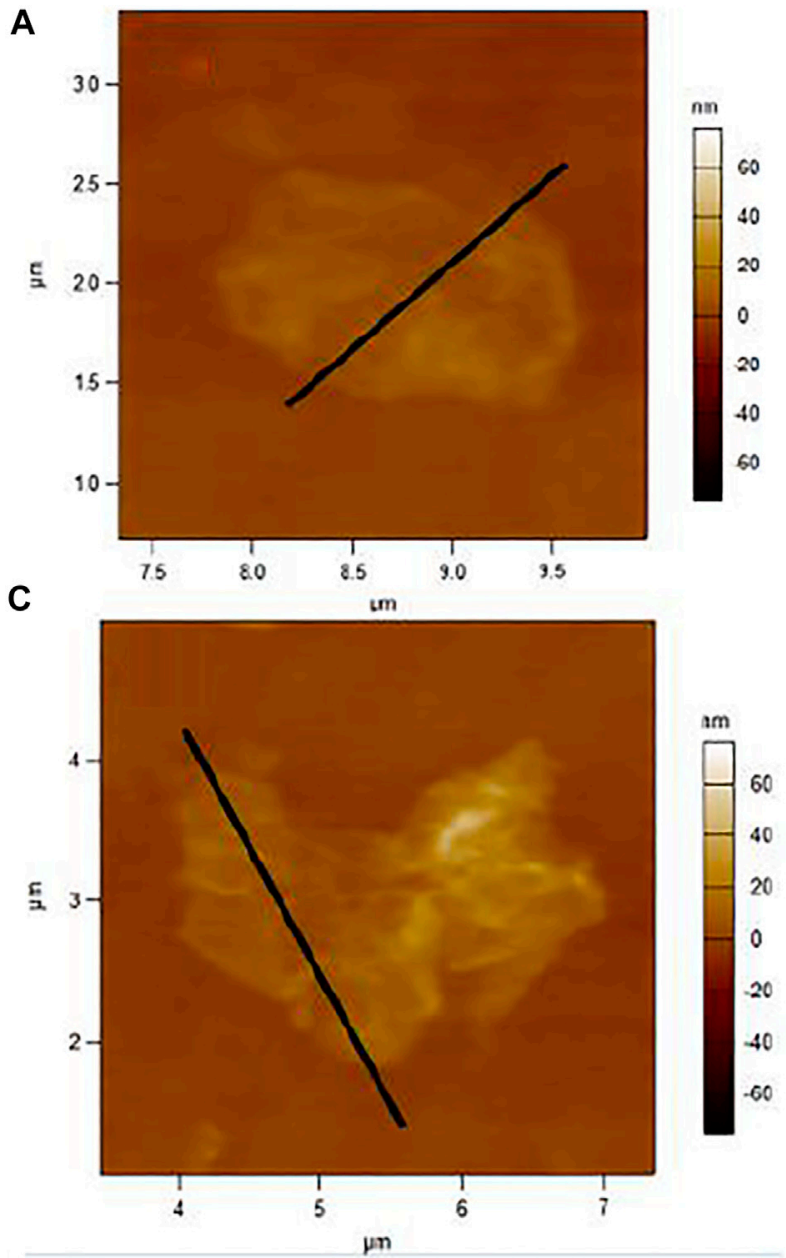

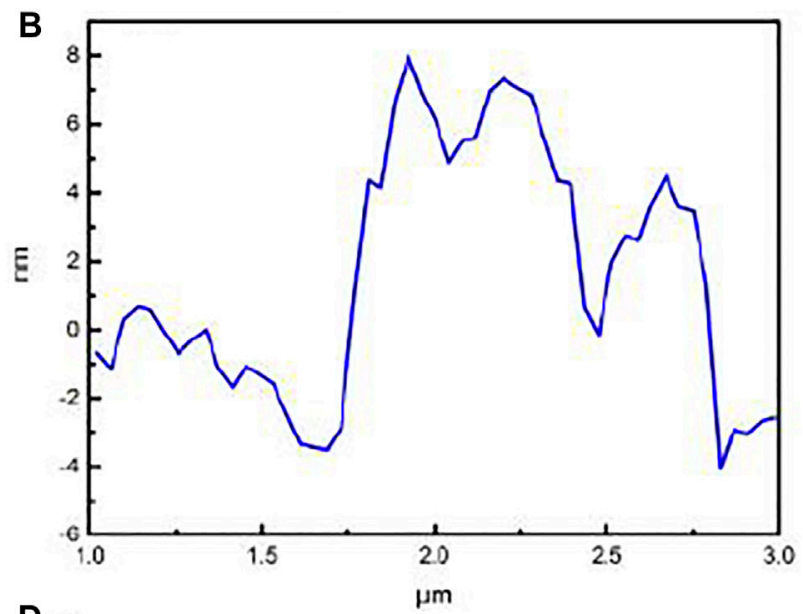

D

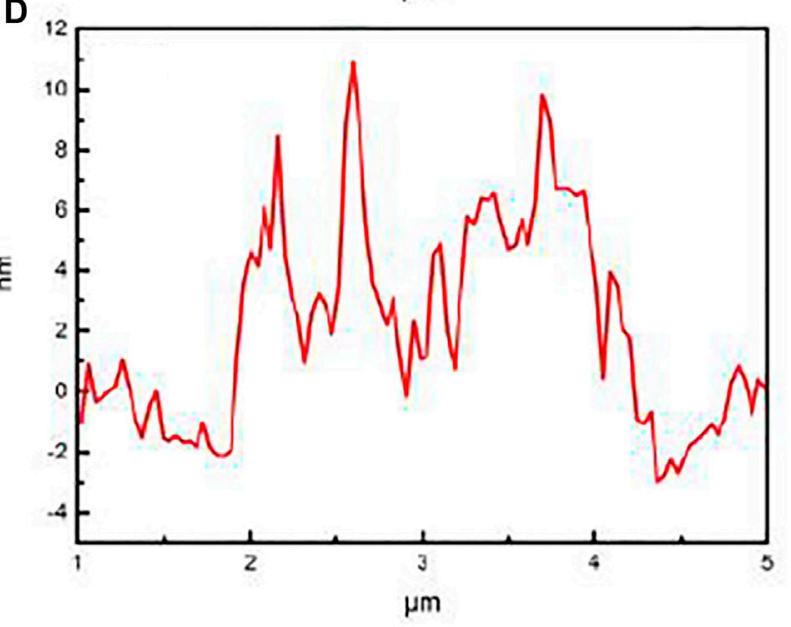

FIGURE 3 | AFM images of films deposited on a silicon wafer through drop-casting: (A, B) GO; (C, D) GO-APS.

$G$ peak remained unchanged, indicating that the modification process connects the APS molecules and the GO surface by chemical bonds without significantly changing the structure of GO. The increase of the $\mathrm{D} / \mathrm{G}$ intensity ratio (ID/IG) in the Raman spectrum of GO-APS films mean the size of the $\mathrm{sp}^{2}$ hybrid structure of the carbon zone (graphite crystallite) decreases and disorder increases (Gómez-Navarro et al., 2007). The GO fragmentation is due to the chemical reduction of the silane coupling agent (Singh et al., 2013; Tang et al., 2013; Liu et al., 2015b), consistent with the AFM results.

The adhesion strength of the GO, APS, and GO-APS films was measured by the pull-off tests, as shown in Figure 6. There is a significant difference in the adhesion strength of the three films. The GO film demonstrates low adhesion strength $(\sim 9.2 \mathrm{MPa})$ compared with the adhesion strength of the GO-APS films $(\sim 20.4 \mathrm{MPa})$. The adhesion strength of the APS film is $22.5 \mathrm{MPa}$, suggesting good adhesion of the film. The high adhesion strength of the APS film implies that the increase in adhesion strength of the GO-APS films must be related to the amount of APS.
Figure 7 displays the depth profiles of elemental analysis across the GO and GO-APS films by the GDOES method. In Figure 7A, the GO covered sample comprises three layers, including the GO outer layer, the magnesium alloy corrosion product layer, and the oxide transition inner layer. Clear $\mathrm{C}$ and $\mathrm{O}$ signals were detected on the surface of the GO sample, corresponding to the GO layer $(\sim 0.17 \mu \mathrm{m})$. It is essential that the $\mathrm{Mg}$ signal be observed across the GO film, demonstrating that the $\mathrm{Mg}$ on the surface of the substrate participates in the GO film-forming reaction. Then both $\mathrm{O}$ and $\mathrm{Mg}$ signals reach a plateau attributed to the corrosion product layer $(\sim 0.4 \mu \mathrm{m})$ sputtering. After that, the decrease in the $\mathrm{O}$ signal and the increase in the $\mathrm{Mg}$ signal confirm the transition from layer to $\mathrm{Mg}$ alloy during sputtering. Finally, the $\mathrm{Mg}$ concentration reached a platform, and the $\mathrm{Al}$ signal disappears due to the alloy's sputtering. In Figure $\mathbf{7 B}$, there is an evident increase in thickness of the GO-APS films (GO layer $\sim 0.17 \mu \mathrm{m}$, GO-APS layer $\sim 0.57 \mu \mathrm{m}$ ) due to the presence of silane chains grafted on the GO surface (the Si signal can be detected). Meanwhile, the decrease in thickness of the corrosion product layer indicates 

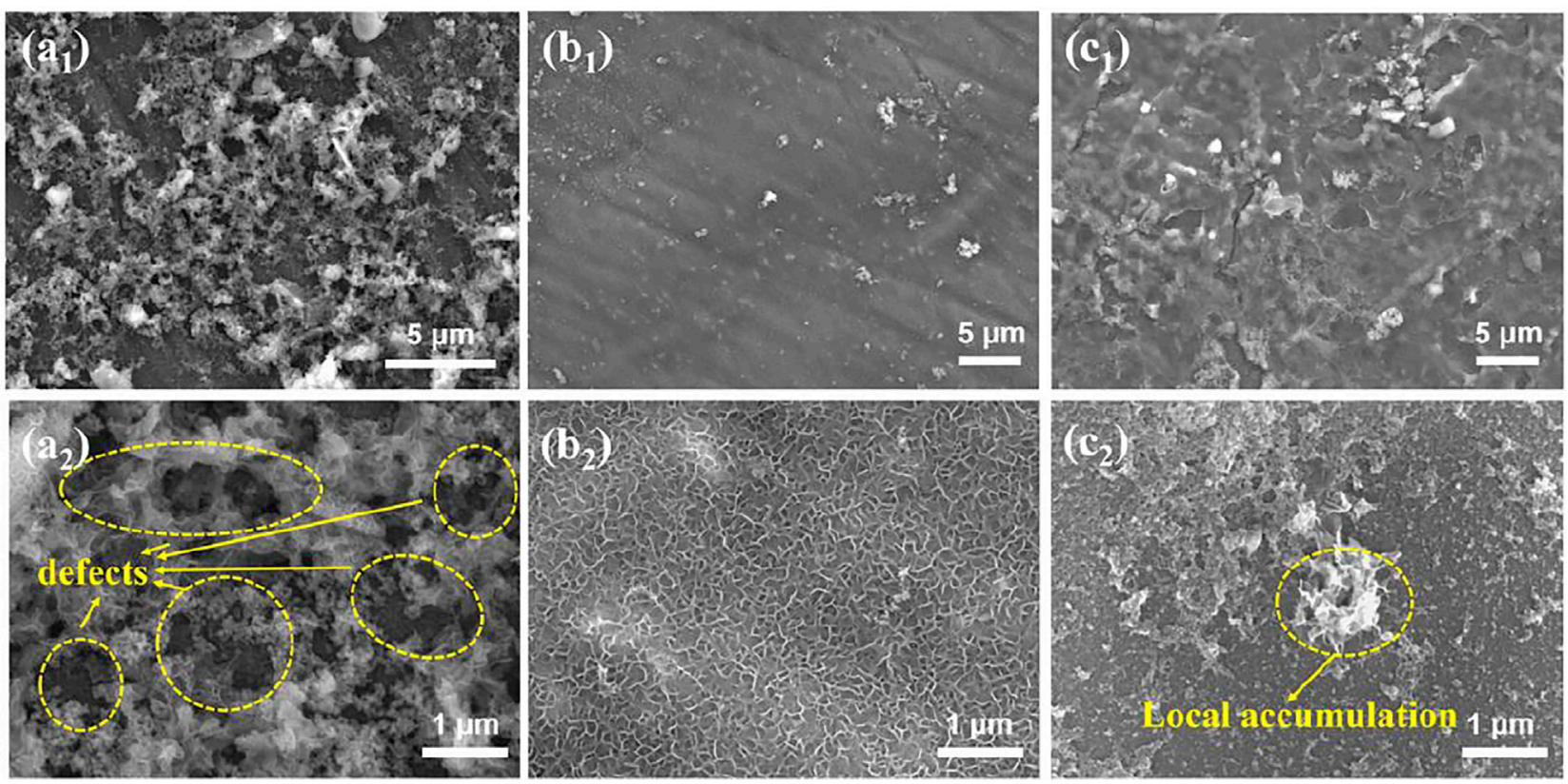

FIGURE 4 | FE-SEM images of film-coated Mg alloy samples: $\left(\mathbf{A}_{\mathbf{1}}, \mathbf{A}_{\mathbf{2}}\right)$ GO film; $\left(\mathbf{B}_{\mathbf{1}}, \mathbf{B}_{\mathbf{2}}\right)$ APS film; $\left(\mathbf{C}_{\mathbf{1}}, \mathbf{C}_{\mathbf{2}}\right)$ GO-APS films.

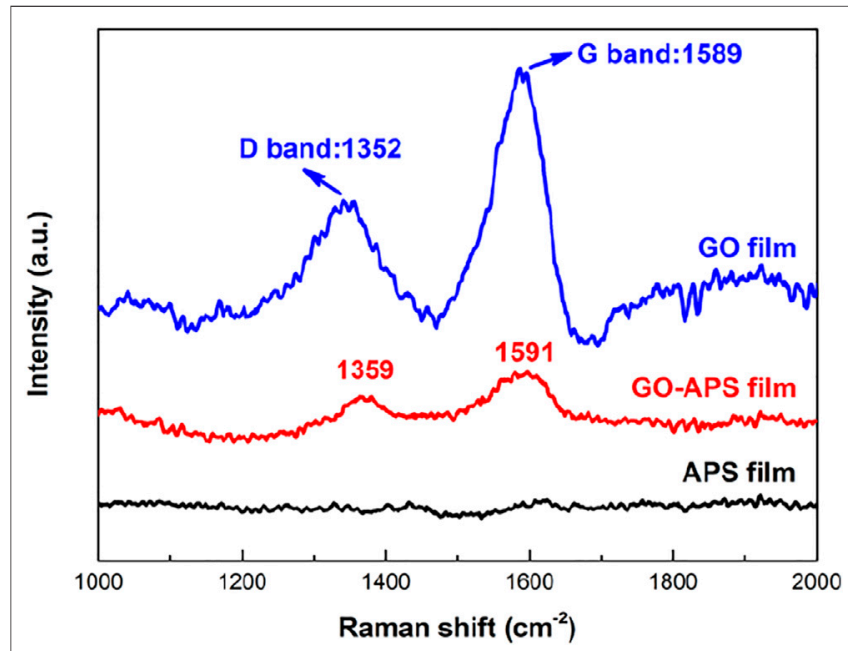

FIGURE 5|Raman spectra of film-coated Mg alloy samples: (A) GO film; (B) APS film; (C) GO-APS film.

that the GO-APS layers can be considered as good physical barrier layers that can provide sufficient protection.

Figure 8 shows the EIS results of bare Mg alloy and GO, APS, and GO-APS film-coated Mg alloy samples immersed for $24 \mathrm{~h}$. In the Bode plots of phase angle, two well-defined time constants can be found in the spectra of different samples. The one appearing at high frequency is contributed by the porous layer, while the other appears at medium frequency due to the barrier layer. It is well known that coatings with a higher $Z$ modulus $(|Z|)$ at lower frequencies exhibit better corrosion resistance on metal substrates (Yu et al., 2015; Ma

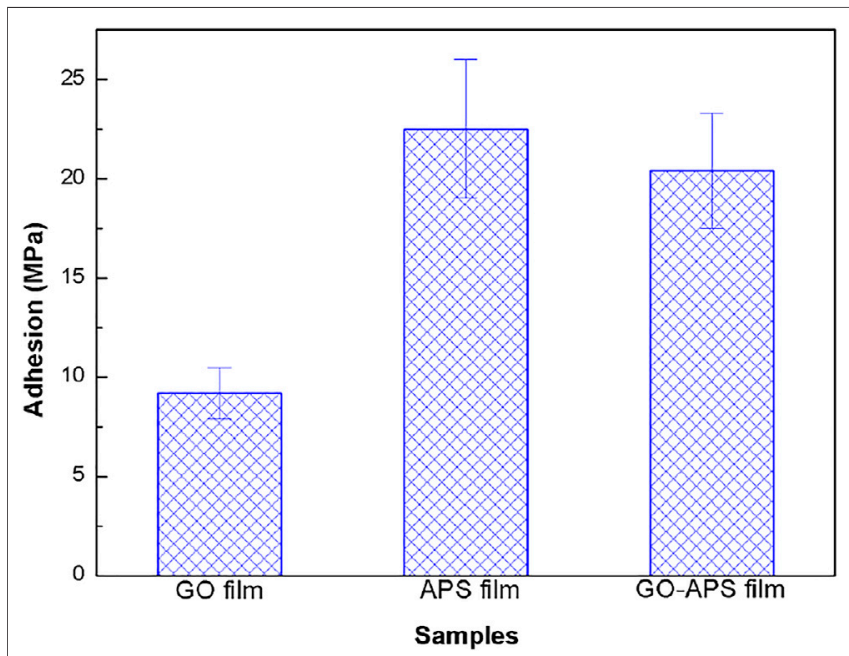

FIGURE 6 | Adhesion results of the pull-off tests of GO, APS, and GOAPS films.

et al., 2016). There is an increase in $|\mathrm{Z}| 0.01 \mathrm{~Hz}$ value the GO-APS films due to the presence of silane chains grafted on the GO surface compared with that of the GO film. The results showed that the APS-modified film significantly improved the corrosion resistance of $\mathrm{Mg}$ alloy. Correspondingly, two capacitor rings of different samples can also be seen in the Nyquist plots, representing the porous layer and the barrier layer, respectively. The size of the capacitor ring represents the degree of corrosion resistance. In Figure 8A, the GOAPS film presents the largest diameter, indicating that the film has the best corrosion resistance. 

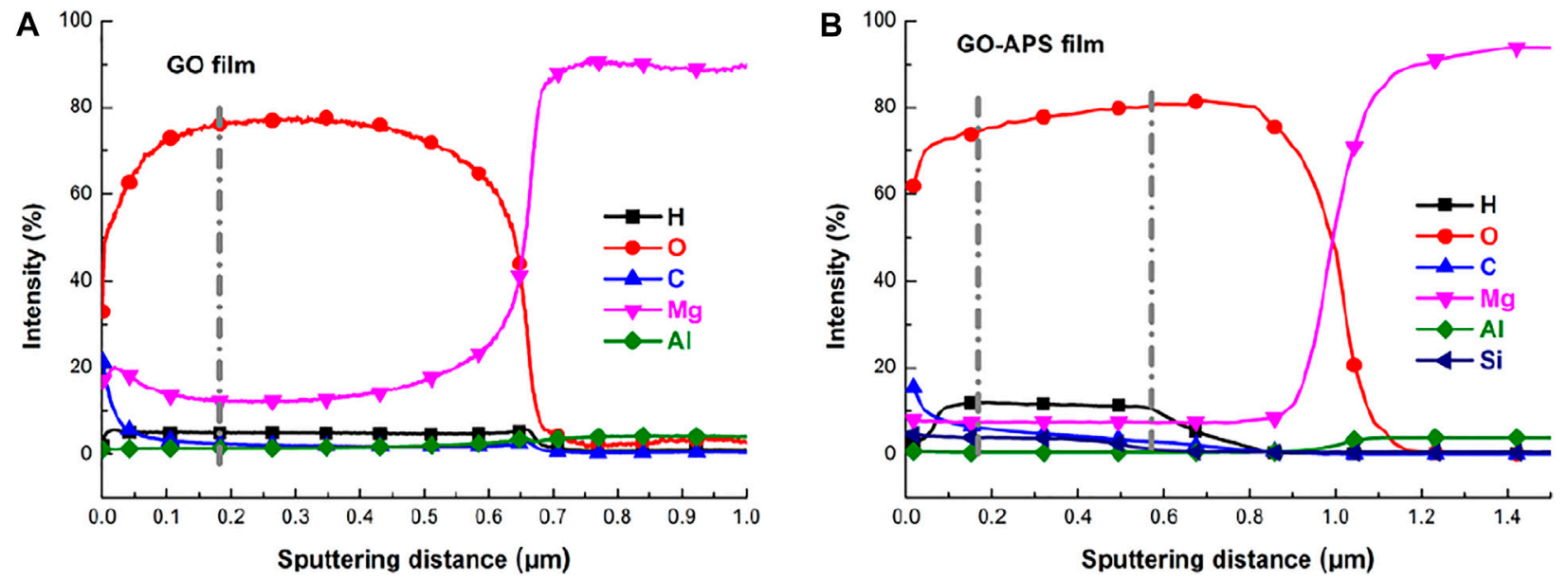

FIGURE 7 | GDOES depth profile of GO and GO-APS film-coated Mg alloy samples: (A) GO film; (B) GO-APS films.
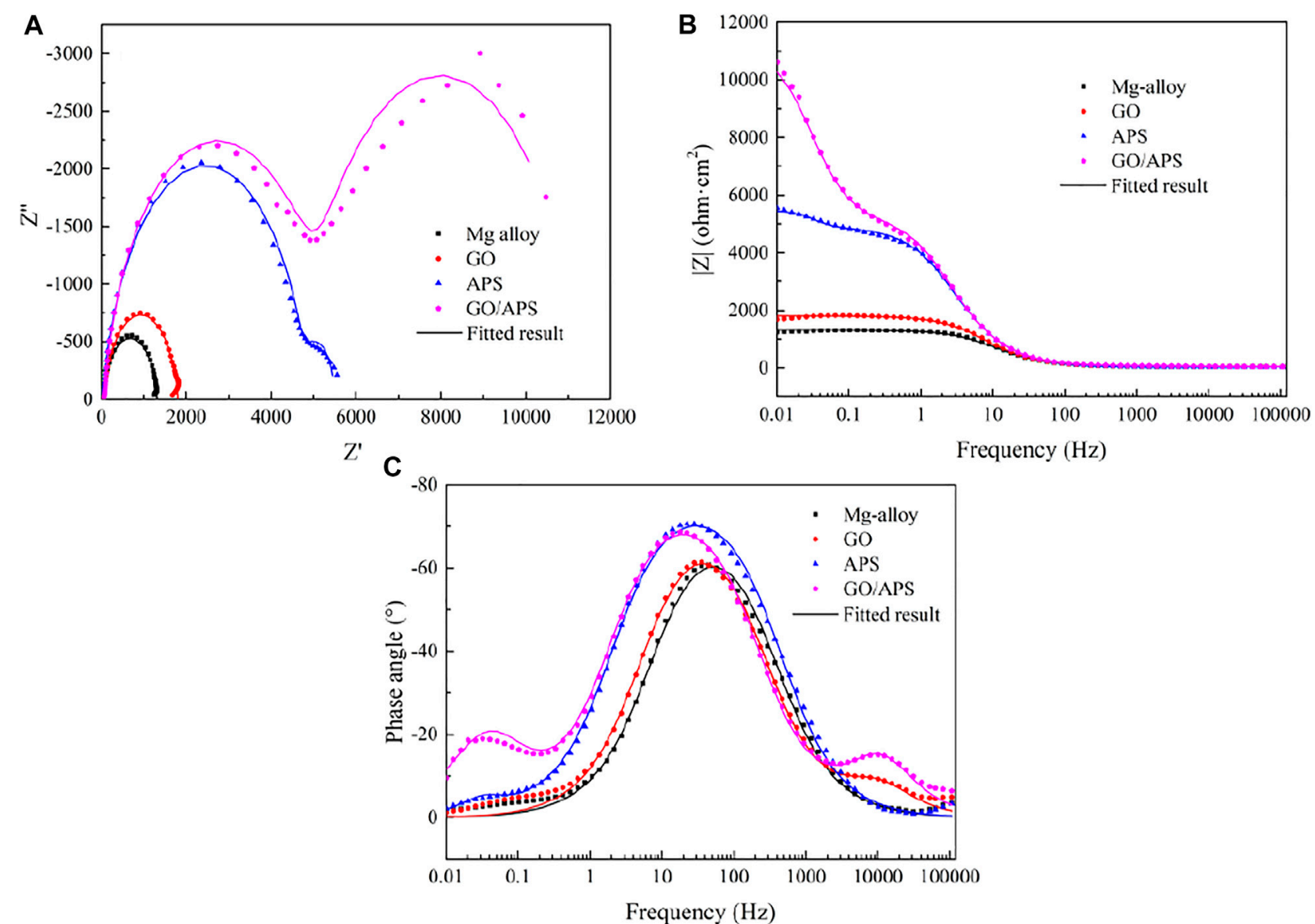

FIGURE 8 | EIS curves and fitted results of bare Mg alloy and GO, APS, and GO-APS film-coated Mg alloy samples after $24 \mathrm{~h}$ of immersion in $0.05 \mathrm{M} \mathrm{NaCl} \mathrm{solution:}$ (A) Nyquist plot; (B) Bode impedance modulus plot; (C) Bode impedance phase angle plot. 

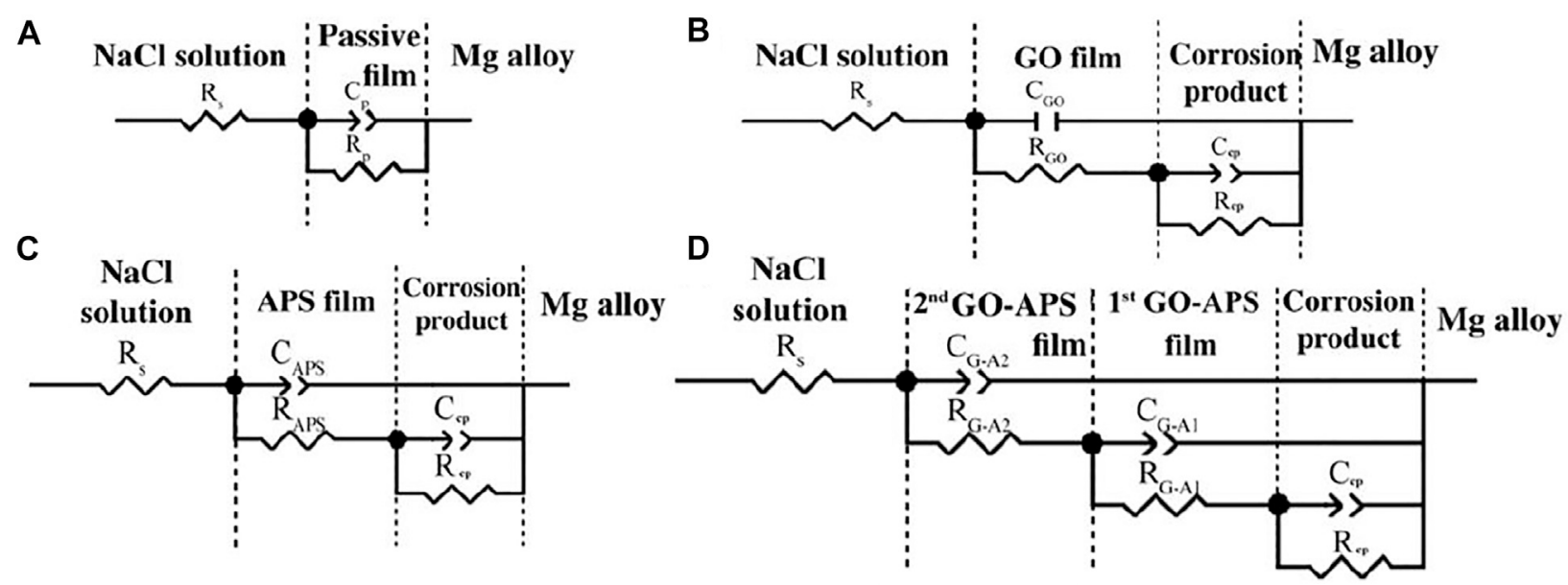

FIGURE 9 | Equivalent circuits of EIS results: (A) bare Mg alloy; (B) GO film-coated Mg alloy; (C) APS film-coated Mg alloy; (D) GO-APS film-coated Mg alloy.

TABLE 1 | Parameter values for ECs of various samples.

Sample

Bare Mg alloy

41.4

$2.6631 \mathrm{E}-5$

1274

$R_{\mathrm{p}} /\left(\Omega \mathrm{cm}^{2}\right)$

$\mathrm{C}_{\mathrm{GO}} /(\mathrm{F})$

$R_{\mathrm{GO}} /\left(\Omega \mathrm{cm}^{2}\right)$

$C_{\text {APS }} /(\mathrm{F})$

$R_{\mathrm{APS}} /\left(\Omega \mathrm{cm}^{2}\right)$

$\mathrm{C}_{\mathrm{G}-\mathrm{A} 2} /(\mathrm{F})$

$R_{\mathrm{G}-\mathrm{A} 2} /\left(\Omega \mathrm{cm}^{2}\right)$

$\mathrm{C}_{\mathrm{G}-\mathrm{A} 1} /(\mathrm{F})$

$R_{\mathrm{G}-\mathrm{A} 1} /\left(\Omega \mathrm{cm}^{2}\right)$

$C_{\mathrm{cp}} /(\mathrm{F})$

$R_{\mathrm{cp}} /\left(\Omega \mathrm{cm}^{2}\right)$

$-$

$-$

-

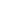

-

$-$

$-$
GO film-coated Mg alloy

APS film-coated Mg alloy

GO-APS

film-coated Mg alloy

- $\quad 2.4594 \mathrm{E}-5$

- $\quad 1744$

42.25
-
-
$1.2443 \mathrm{E}-6$
16.05
-
-
-
-
-
-
$2.4594 \mathrm{E}-5$
1744

42.2

43E-6

8.3614E-3
610.1

42.97

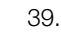

$-$

$-$

$2.2014 \mathrm{E}-5$

4828

-

$-$

- $\quad 2.1302 \mathrm{E}-5$

5242

$9.0208 \mathrm{E}-4$

5879
Figure 8 presents the results obtained from the EIS data of bare $\mathrm{Mg}$ alloy and GO, APS, and GO-APS film-coated Mg alloy. The equivalent circuits (ECs) obtained from the fitted results are revealed in Figure 9. For all samples, $R_{\mathrm{s}}$ in the ECs represent the resistance in $\mathrm{NaCl}$ solution. According to the simulated ECs, the following can be determined: $C_{\mathrm{p}}$ and $R_{\mathrm{p}}$ correspond to the passive film formed on the surface of the $\mathrm{Mg}$ alloy; $C_{\mathrm{cp}}$ and $R_{\mathrm{cp}}$ correspond to the corrosion product layer between the outer film and the $\mathrm{Mg}$ alloy substrate; the GO film coated on the $\mathrm{Mg}$ alloy can be expressed by $C_{\mathrm{GO}}$ and $R_{\mathrm{GO}} ; C_{\mathrm{APS}}$ and $R_{\mathrm{APS}}$ represent the APS film; and the double layer films can be deduced for the GO-APS film-coated $\mathrm{Mg}$ alloy, which is signified by $C_{\mathrm{G}-\mathrm{A} 1}$ and $\mathrm{C}_{\mathrm{G}-\mathrm{A} 2}$.

Each value of the elements in ECs is exhibited in Table 1. Regarding the GO film on $\mathrm{Mg}$ alloy, $R_{\mathrm{GO}}$ and $R_{\mathrm{cp}}$ demonstrate the rise in corrosion resistance due to the GO film. The high value of $R_{\mathrm{cp}}$ indicates the corrosion product between the GO film and $\mathrm{Mg}$ alloy substrate dominated in the protection from corrosion. The low value of $R_{\mathrm{GO}}$ could be caused by the cracks on the GO film (Prasai et al., 2012; Yu et al., 2015). Also, the higher $R_{\mathrm{cp}}$ value of
TABLE 2 | Comparison of corrosion resistance of GO-based films/coatings on Mg alloys.

\begin{tabular}{llcl}
\hline Substrate & Films/coatings & $\mathbf{R}_{\mathbf{c t}} / \mathbf{R}_{\mathbf{c p}}\left(\mathbf{\Omega} \mathbf{c m}^{\mathbf{2}}\right)$ & \multicolumn{1}{c}{ Ref } \\
\hline AZ31 & HQ/GO/MgO & 243.6 & Soliman et al. (2020) \\
AZ31 & GO & 992 & Ikhe et al. (2016) \\
PPFS/GO & & 3598 & \\
AZ31 & HAVGO & 329.4 & Peng et al. (2020) \\
Mg-Zn-Ca & rGO-PVA & 1804 & Chu et al. (2019) \\
GO-PVA & & 285.3 & \\
AZ31 & EPD-GO & 873.5 & Maqsood et al. (2020) \\
AZ31 & GO-APS & 5879 & This article
\end{tabular}

the GO film-coated $\mathrm{Mg}$ alloy than the $R_{\mathrm{p}}$ value of the bare $\mathrm{Mg}$ alloy proved the adequate protection of the GO film from corrosion. As for the APS film-coated Mg alloy, in the same way, the high $R_{\mathrm{APS}}$ and $R_{\mathrm{cp}}$ values also explained the protective effect of the APS film from corrosive $\mathrm{NaCl}$ solution. In the case of the silane-modified GO film, the corrosion resistances of first GO-APS layers and the corrosion product layer between 
the GO-APS films and Mg alloy substrate are much higher than those of the GO film-coated $\mathrm{Mg}$ alloy, indicating that silane modification greatly improved the resistance of the GO film from corrosion. Besides, the higher $R_{\mathrm{G}-\mathrm{A} 1}$ and $R_{\mathrm{cp}}$ values than the $R_{\mathrm{G}-\mathrm{A} 2}$ value demonstrate that the corrosion resistance of GO-APS films is dominated by the first layer of the GO-APS films and the corrosion product formed in the process of immersion in GOAPS sol. Therefore, the GO-APS film exhibits good corrosion protection and is superior to most of the GO-based anticorrosive coatings on magnesium alloys, as shown in Table 2.

The possible protective mechanism of silane-modified GO films is as follows:

1) The surface modification of silane reduces the conductivity of GO and inhibits the promotion of GO to metal corrosion at film defects (Yu et al., 2015).

2) The impermeability of GO improves the physical barrier property of the film and prevents the infiltration and erosion of the corrosive medium (Chu et al., 2019; Maqsood et al., 2020).

3) The corrosion product layer was formed at the interface between the GO-silane layer and the magnesium alloy substrate, which formed the synergistic protective effect.

\section{CONCLUSION}

The surface modification of GO was carried out by using APS. The results showed that APS successfully modified the surface of $\mathrm{GO}$, and the prepared film significantly improved the corrosion resistance of the magnesium alloy. Results indicated that GO

\section{REFERENCES}

Aneja, K. S., Böhm, H. L. M., Khanna, A. S., and Böhm, S. (2017). Functionalised Graphene as a Barrier against Corrosion. FlatChem. 1, 11-19. doi:10.1016/ j.flatc.2016.08.003

Chang, C.-H., Huang, T.-C., Peng, C.-W., Yeh, T.-C., Lu, H.-I., Hung, W.-I., et al. (2012). Novel Anticorrosion Coatings Prepared from Polyaniline/ graphene Composites. Carbon 50, 5044-5051. doi:10.1016/ j.carbon.2012.06.043

Chu, J. H., Tong, L. B., Wen, M., Jiang, Z. H., Wang, K. S., and Zhang, H. J. (2019). Graphene Oxide Film as a Protective Barrier for Mg alloy: Worse or Better Is Dependent on a Chemical Reduction Process. Carbon 145, 389-400. doi:10.1016/j.carbon.2019.01.037

Daavari, M., Atapour, M., Mohedano, M., Arrabal, R., Matykina, E., and Taherizadeh, A. (2021). Biotribology and Biocorrosion of MWCNTsReinforced PEO Coating on AZ31B Mg alloy. Surf. Inter. 22, 100850. doi:10.1016/j.surfin.2020.100850

Fernández-Hernán, J. P., López, A. J., Torres, B., and Rams, J. (2021). Influence of Roughness and Grinding Direction on the Thickness and Adhesion of Sol-Gel Coatings Deposited by Dip-Coating on AZ31 Magnesium Substrates. A Landau-Levich Equation Revision. Surf. Coat. Tech. 408, 126798. doi:10.1016/j.surfcoat.2020.126798

Ferrari, A. C., Meyer, J. C., Scardaci, V., Casiraghi, C., Lazzeri, M., Mauri, F., et al. (2006). Raman Spectrum of Graphene and Graphene Layers. Phys. Rev. Lett. 97, 187401. doi:10.1103/physrevlett.97.187401

Gnedenkov, A. S., Sinebryukhov, S. L., Mashtalyar, D. V., and Gnedenkov, S. V. (2016). Protective Properties of Inhibitor-Containing Composite Coatings on a Mg alloy. Corrosion Sci. 102, 348-354. doi:10.1016/j.corsci.2015.10.026 films could not be applied on magnesium alloy AZ31 because of the formed corrosion product layer and unavoidable defects. In contrast, APS plays an important role in improving the uniformity and adhesion of the GO film and decreasing the thickness of the corrosion product layer. The GO-APS films can be formed as a good physical barrier layer that can provide effective corrosion protection. This method provides a new idea for the application of graphene-based thin films on the magnesium alloy surface.

\section{DATA AVAILABILITY STATEMENT}

The original contributions presented in the study are included in the article/supplementary material; further inquiries can be directed to the corresponding authors.

\section{AUTHOR CONTRIBUTIONS}

All authors listed have made a substantial, direct, and intellectual contribution to the work and approved it for publication.

\section{FUNDING}

This work was supported by the Natural Science Foundation of Beijing (Grant Nos. 2182017 and 2202017), Science and Technology Project of Beijing Education Commission (KM201910017004), and URT program of Beijing Institute of Petrochemical Technology (2021J00135 and 2021J00134).

Gómez-Navarro, C., Weitz, R. T., Bittner, A. M., Scolari, M., Mews, A., Burghard, M., et al. (2007). Electronic Transport Properties of Individual Chemically Reduced Graphene Oxide Sheets. Nano Lett. 7, 3499-3503. doi:10.1021/ nl072090c

Hernández-Barrios, C. A., Saavedra, J. A., Higuera, S. L., Coy, A. E., and Viejo, F. (2020). Effect of Cerium on the Physicochemical and Anticorrosive Features of TEOS-GPTMS Sol-Gel Coatings Deposited on the AZ31 Magnesium alloy. Surf. Inter. 21, 100671. doi:10.1016/j.surfin.2020.100671

Hsieh, Y.-P., Hofmann, M., Chang, K.-W., Jhu, J. G., Li, Y.-Y., Chen, K. Y., et al. (2014). Complete Corrosion Inhibition through Graphene Defect Passivation. ACS Nano 8, 443-448. doi:10.1021/nn404756q

Ikhe, A. B., Kale, A. B., Jeong, J., Reece, M. J., Choi, S.-H., and Pyo, M. (2016). Perfluorinated Polysiloxane Hybridized with Graphene Oxide for Corrosion Inhibition of AZ31 Magnesium alloy. Corrosion Sci. 109, 238-245. doi:10.1016/ j.corsci.2016.04.010

Jo, M., Lee, H. C., Lee, S. G., and Cho, K. (2017). Graphene as a Metal Passivation Layer: Corrosion-Accelerator and Inhibitor. Carbon 116, 232-239. doi:10.1016/ j.carbon.2017.02.008

Kyhl, L., Nielsen, S. F., Čabo, A. G., Cassidy, A., Miwa, J. A., and Hornekær, L. (2015). Graphene as an Anti-corrosion Coating Layer. Faraday Discuss. 180, 495-509. doi:10.1039/c4fd00259h

Lei, J., Hu, Y., Liu, Z., Cheng, G. J., and Zhao, K. (2017). Defects Mediated Corrosion in Graphene Coating Layer. ACS Appl. Mater. Inter. 9, 11902-11908. doi:10.1021/acsami.7b01539

Liu, J., Hua, L., Li, S., and Yu, M. (2015). Graphene Dip Coatings: An Effective Anticorrosion Barrier on Aluminum. Appl. Surf. Sci. 327, 241-245. doi:10.1016/ j.apsusc.2014.11.187

Liu, J., Zhang, Y., Yu, M., Li, S., Xue, B., and Yin, X. (2015). Influence of Embedded ZnAlCe-No3- Layered Double Hydroxides on the Anticorrosion Properties of 
Sol-Gel Coatings for Aluminum alloy. Prog. Org. Coat. 81, 93-100. doi:10.1016/ j.porgcoat.2014.12.015

Ma, B., Rodriguez, R. D., Ruban, A., Pavlov, S., and Sheremet, E. (2019). The Correlation between Electrical Conductivity and Second-Order Raman Modes of Laser-Reduced Graphene Oxide. Phys. Chem. Chem. Phys. 21, 10125-10134. doi:10.1039/c9cp00093c

Ma, Y., Di, H., Yu, Z., Liang, L., Lv, L., Pan, Y., et al. (2016). Fabrication of SilicaDecorated Graphene Oxide Nanohybrids and the Properties of Composite Epoxy Coatings Research. Appl. Surf. Sci. 360, 936-945. doi:10.1016/ j.apsusc.2015.11.088

Maqsood, M. F., Raza, M. A., Ghauri, F. A., Rehman, Z. U., and Ilyas, M. T. (2020). Corrosion Study of Graphene Oxide Coatings on AZ31B Magnesium alloy. J. Coat. Technol. Res. 17, 1321-1329. doi:10.1007/s11998-020-00350-3

Matinlinna, J. P., Lung, C. Y. K., and Tsoi, J. K. H. (2018). Silane Adhesion Mechanism in Dental Applications and Surface Treatments: A Review. Dental Mater. 34, 13-28. doi:10.1016/j.dental.2017.09.002

Pan, F., Yang, M., and Chen, X. (2016). A Review on Casting Magnesium Alloys: Modification of Commercial Alloys and Development of New Alloys. J. Mater. Sci. Tech. 32, 1211-1221. doi:10.1016/j.jmst.2016.07.001

Peng, F., Zhang, D., Wang, D., Liu, L., and Liu, X. (2020). Enhanced Corrosion Resistance and Biocompatibility of Magnesium alloy by Hydroxyapatite/ graphene Oxide Bilayer Coating. Mater. Lett. 264, 127-322. doi:10.1016/ j.matlet.2020.127322

Prasai, D., Tuberquia, J. C., Harl, R. R., Jennings, G. K., and Bolotin, K. I. (2012). Graphene: Corrosion-Inhibiting Coating. ACS Nano 6, 1102-1108. doi:10.1021/nn203507y

Ramezanzadeh, B., Ahmadi, A., and Mahdavian, M. (2016). Enhancement of the Corrosion protection Performance and Cathodic Delamination Resistance of Epoxy Coating through Treatment of Steel Substrate by a Novel Nanometric Sol-Gel Based Silane Composite Film Filled with Functionalized Graphene Oxide Nanosheets. Corrosion Sci. 109, 182-205. doi:10.1016/ j.corsci.2016.04.004

Sanjid, A., Banerjee, P. C., and Raman, R. K. S. (2019). Multi-layer Graphene Coating for Corrosion Resistance of Monel 400 alloy in Chloride Environment. Surf. Coat. Tech. 370, 227-234. doi:10.1016/j.surfcoat.2019.04.077

Singh, B. P., Nayak, S., Nanda, K. K., Jena, B. K., Bhattacharjee, S., and Besra, L. (2013). The Production of a Corrosion Resistant Graphene Reinforced Composite Coating on Copper by Electrophoretic Deposition. Carbon 61, 47-56. doi:10.1016/j.carbon.2013.04.063

Soliman, H., Qian, J., Tang, S., Xian, P., and Wan, G. (2020). Hydroxyquinoline/ nano-graphene Oxide Composite Coating of Self-Healing Functionality on Treated Mg Alloys AZ31. Surf. Coat. Tech. 385, 125-395. doi:10.1016/ j.surfcoat.2020.125395

Stankovich, S., Dikin, D. A., Piner, R. D., Kohlhaas, K. A., Kleinhammes, A., Jia, Y., et al. (2007). Synthesis of Graphene-Based Nanosheets via Chemical Reduction of Exfoliated Graphite Oxide. Carbon 45, 1558-1565. doi:10.1016/ j.carbon.2007.02.034

Sun, W., Wang, L., Wu, T., Wang, M., Yang, Z., Pan, Y., et al. (2015). Inhibiting the Corrosion-Promotion Activity of Graphene. Chem. Mater. 27, 2367-2373. doi:10.1021/cm5043099
Tang, L.-C., Wan, Y.-J., Yan, D., Pei, Y.-B., Zhao, L., Li, Y.-B., et al. (2013). The Effect of Graphene Dispersion on the Mechanical Properties of Graphene/ epoxy Composites. Carbon 60, 16-27. doi:10.1016/j.carbon.2013.03.050

Wan, Y.-J., Gong, L.-X., Tang, L.-C., Wu, L.-B., and Jiang, J.-X. (2014). Mechanical Properties of Epoxy Composites Filled with Silane-Functionalized Graphene Oxide. Composites A: Appl. Sci. Manufacturing 64, 79-89. doi:10.1016/ j.compositesa.2014.04.023

Wu, G., Ibrahim, J. M., and Chu, P. K. (2013). Surface Design of Biodegradable Magnesium Alloys - A Review. Surf. Coat. Tech. 233, 2-12. doi:10.1016/ j.surfcoat.2012.10.009

Yu, M., Xue, B., Liu, J., Li, S., and Zhang, Y. (2015). Electrophoretic Deposition of Hybrid Coatings on Aluminum alloy by Combining 3aminopropyltrimethoxysilan to Silicon-Zirconium Sol Solutions for Corrosion protection. Thin Solid Films 590, 33-39. doi:10.1016/j.tsf.2015.07.055

Yu, Y.-H., Lin, Y.-Y., Lin, C.-H., Chan, C.-C., and Huang, Y.-C. (2014). Highperformance Polystyrene/graphene-Based Nanocomposites with Excellent Anti-corrosion Properties. Polym. Chem. 5, 535-550. doi:10.1039/c3py00825h

Zainal Abidin, N. I., Rolfe, B., Owen, H., Malisano, J., Martin, D., Hofstetter, J., et al. (2013). The In Vivo and In Vitro Corrosion of High-Purity Magnesium and Magnesium Alloys WZ21 and AZ91. Corrosion Sci. 75, 354-366. doi:10.1016/ j.corsci.2013.06.019

Zhang, Y., Yu, P., Wang, J., Li, Y., Chen, F., Wei, K., et al. (2018). LDHs/Graphene Film on Aluminum Alloys for Active protection. Appl. Surf. Sci. 433, 927-933. doi:10.1016/j.apsusc.2017.10.126

Zhou, Z., Zheng, B., Lang, H., Qin, A., and Ou, J. (2020). Corrosion Resistance and Biocompatibility of Polydopamine/hyaluronic Acid Composite Coating on AZ31 Magnesium alloy. Surf. Inter. 20, 100560. doi:10.1016/j.surfin.2020.100560

Conflict of Interest: Author XH was employed by China United Testing \& Certification Co., Ltd.

The remaining authors declare that the research was conducted in the absence of any commercial or financial relationships that could be construed as a potential conflict of interest.

The handling editor declared a past co-authorship with one of the authors YZ.

Publisher's Note: All claims expressed in this article are solely those of the authors and do not necessarily represent those of their affiliated organizations, or those of the publisher, the editors, and the reviewers. Any product that may be evaluated in this article, or claim that may be made by its manufacturer, is not guaranteed or endorsed by the publisher.

Copyright (๑ 2021 Zhang, Wang, Zhang, Wei, Zhang, Hao and Chen. This is an open-access article distributed under the terms of the Creative Commons Attribution License (CC BY). The use, distribution or reproduction in other forums is permitted, provided the original author(s) and the copyright owner(s) are credited and that the original publication in this journal is cited, in accordance with accepted academic practice. No use, distribution or reproduction is permitted which does not comply with these terms. 